\title{
Exploring Digital Competence Requirements for Junior Financial Analysts in the UK Banking Industry
}

\author{
Matthias Murawski ${ }^{(\bowtie)}$, Mahdieh Darvish, Charlotte Marie Prinz, \\ and Markus Bick \\ ESCP Business School Berlin, Berlin, Germany \\ \{mmurawski,mdarvish,mbick\}@escpeurope.eu, \\ charlotte_marie.prinz@edu.escpeurope.eu
}

\begin{abstract}
Although young adults familiar with digital technology join the workforce and bring in more advanced digital competences, the demand for digital competences in many industries increases even faster. In this study, we place the focus on the banking industry in the United Kingdom and aim for exploring those digital competences that are required for junior financial analysts. For this purpose, we apply a qualitative research approach which consists of two steps. First, we analyze job advertisements and code the identified competences by using the DigComp 2.0 framework. Second, we conduct interviews to validate and discuss our findings from the previous step. Our analysis reveals that the most important required competence categories are information and data literacy, followed by digital content creation. This paper contributes to the research field of digital competences and provides relevant insights for, amongst others, applicants, HR professionals, and training and education providers.
\end{abstract}

Keywords: Banking industry $\cdot$ Digital competences $\cdot$ DigComp 2.0

framework $\cdot$ Financial analysts $\cdot$ Interviews $\cdot$ Job advertisements $\cdot$ Qualitative analysis

\section{Introduction}

Today's young adults are raised in an environment in which they are surrounded by technology, and they consequently possess different digital competences compared to people from older generations [1]. Thus, entry-level workers bring new competences into the workforce [2]. At the same time, work becomes more digital: computer technology substitutes workers in performing routine tasks that can be described with programmed rules, while also complementing workers in executing non-routine tasks demanding flexibility, creativity, generalized problem-solving capabilities and complex communications [3].

While the level of digital competences increases in the workforce, the demand for digital competences seems to grow even faster [4, 5]. According to Newhouse, society is currently facing a period in which technological capabilities accelerate so swiftly that talent and knowledge cannot keep up, which consequently leads to a digital competence gap [6]. 
The financial industry has been, and still is, in the center of innovation concerning information systems and technologies [7]. Information technology (IT) investments in the financial sector are among the highest due to the enormous profit potentials within the industry as well as the economic incentives for substituting expensive human labor by cheaper computers [8]. Furthermore, digital strategies are part of banks' core strategic decision making and hiring the right people to work within a more digital environment is of central importance [9]. Consequently, the financial sector has also been one of the first sectors to experience challenges with acquiring people possessing the right digital competences as well as managing the digital competences of the existing workforce. A Capgemini survey from 2017 shows that $62 \%$ of the banks see the digital talent gap widening, which is the highest rate among all other industries analyzed (e.g. automotive, retail, consumer products, telecom) [10]. However, considering the specificities of the technological applications in the banking industry, the question remains what type of digital competences are needed and required in this field. Scholars in the information systems discipline have been researching the required digital competences for specific occupational groups for a long time. For instance, recent studies have already addressed digital competences of communicators or data professionals $[5,11]$. Other studies emphasize the general need for further research on this topic [4].

In this context, we focus on the occupation financial analyst which has not been investigated in other academic studies, yet. More detailed, we consider junior financial analyst which we define as financial analysts with less than three years of job experience (including graduates). This selection is based on two assumptions formulated in the work of Rynes et al. [12]. First, applicants for entry-level or junior positions have less concrete "proof" of their ability to work on the job. It can thus be assumed that the digital competence requirements are stated more clearly and precisely in job descriptions (which build the basis for our analysis, see Sect. 3) while experienced hires have to show their competencies through work samples. Second, graduate hires are a longterm investment for companies, as their productivity levels are significantly lower in the beginning than more experienced hires. It can therefore be assumed that companies not only require the competences for these entry-level positions that are relevant for their current responsibilities, but they also look at the suitability of candidates for further career steps. Looking at entry level position thus also gives insights into medium- and long-term competence requirements.

Following similar research [e.g. 5], we limit our study to a specific geographic region - in our case the United Kingdom (UK). The UK shows a high level of technology-related jobs, especially in the financial sector, along with an increasing demand for digital competences. Thus, the research question (RQ) of this paper is:

$R Q:$ Which digital competences are required for junior financial analysts in the UK banking industry?

The paper is structured as follows. A review of the existing literature in connection to the research question provides information on the definition of digital competence and the theoretical background of the topic in Sect. 2. Our research design is laid out in Sect. 3. Subsequently, the findings of the data analyses are presented and discussed (Sect. 4), before the paper ends with some concluding remarks in Sect. 5. 


\section{Literature Review}

We started our literature review with the objective to elaborate the current state of research on digital competences. Thus, the term "digital competence*" was searched for in business and information system online databases such as EBSCO, JSTOR, WILEY, Springer and ScienceDirect, which led to only a few results, mostly related to educational purposes and limited to a specific geographical region defining and measuring digital competences specifically in connection to the local culture. By adding terms such as "financial analyst", the searches led to no (peer-reviewed) results. Consequently, the scope was extended to non-peer-reviewed publications, e.g., reports by consultancies such as Deloitte and McKinsey \& Company addressing digital competences in the finance sector.

\subsection{Definition of Digital Competences and the DigComp 2.0 Framework}

The term digital competence is still relatively recent. Instead of a definable construct, it can be understood as a boundary concept applicable to various contexts but always related to skills and practices required to use new technologies in a meaningful way [13]. The idea of understanding and being able to operate technologies is however concomitant with their invention and use in the workplace and society. For example, Calvani et al. [14] suggest a definition of digital competence involving the flexibility to explore new technologies and the ability to select and evaluate data critically to solve problems and gain knowledge. Ferrari [15] applies the KSA framework of competence to define digital competences as a set of required knowledge, skills and attitudes to use information and communication technology (ICT) and digital media to perform tasks such as information management and communication. Furthermore, most definitions include content creating and sharing, building knowledge effectively and being critical as well as reflective when using IT for work, leisure and communication $[16,17]$.

Aside from its definition, another important question is how to measure digital competences. For this purpose, an updated digital competence framework (the socalled DigComp 2.0 framework) was developed and published by the European Commission, consisting of five key categories and 21 subcategories defining digital competences from an institutional perspective [18].

In this paper, we will rely our analysis on the DigComp 2.0 framework as presented in Table 1. It is one of the most recent, well-known and up-to-date frameworks covering a wide range of competence areas and has been the basis of many studies in different disciplines such as education and healthcare [19-21]. It is also a very appropriate framework as it covers a wide range of competence areas and accordingly is rather exhaustive. Another advantage of using the DigComp 2.0 framework is that it allows comparability between both different occupations and studies conducted at different points of time. 
Table 1. DigComp 2.0 framework [18]

\begin{tabular}{l|l}
\hline Categories & Subcategories \\
\hline 1. Information and data & 1. Browsing, searching and filtering data, information and \\
& digital content \\
& 2. Evaluating data, information and digital content \\
& 3. Managing data, information and digital content \\
\hline 2. Communication and & 4. Interacting through digital technologies \\
collaboration & 5. Sharing through digital technologies \\
& 6. Engaging in citizenship through digital technologies \\
& 7. Engaging in citizenship through digital technologies \\
& 8. Netiquette \\
\hline 3. Digital content creation & 10. Denaging digital identity \\
& 11. Integrating and re-elaborating digital content \\
& 12. Copyright and licenses \\
& 13. Programming \\
\hline 4. Safety & 14. Protecting devices \\
& 15. Protecting personal data and privacy \\
& 16. Protecting health and well-being \\
& 17. Protecting the environment \\
\hline 5. Problem solving & 18. Solving technical problems \\
& 19. Identifying needs and technological responses \\
& 20. Creatively using digital technologies \\
& 21. Identifying digital competence gaps \\
\hline
\end{tabular}

\subsection{Digital Competences of Financial Analysts}

Due to novelty and specification of the topic there are hardly any studies addressing digital competences required for financial analysts in the banking industry. Existing ones are mainly not of academic (i.e., double-blind, peer-reviewed) nature, such as consultancy reports.

For example. McKinsey \& Company analyze the shift in competence requirements in banking and insurance, among other sectors, in a discussion-paper [22]. Considering the banking industry, a growth in technological skills, especially in data analytics, is identified. As a result, the need for a workforce with advanced technology skills will grow. In this context, recent studies show that there is a shortage of supply of professionals who are able to deal with data appropriately [5].

A Deloitte survey shows that finance leaders of the future will have to gain new competences to frame the function in a technology-driven environment [8]. In addition, the Deloitte study elaborates that many CFOs see a substantial shift in the tasks of the finance workforce toward analysis, prediction, and decision support. 


\section{Research Design}

The first part of our study aims at addressing the research question through a qualitative content analysis of online job advertisements. The results of this analysis are subsequently checked for validity through expert interviews in the second empirical part of our study. These interviews were also conducted to gain insights into possible explanations behind the primary findings of the content analysis.

\subsection{Analysis of Job Advertisements}

\subsubsection{Data Collection}

Similar to other studies that aimed for identifying required competences, we used job advertisements as the source of data to gain insights into the competence requirements for financial analysts [5, 23]. 50 job advertisements were taken from currently open junior positions in the UK job market in January 2019.

The data was collected from indeed.co.uk, a widely used online job portal in the UK and one of the biggest job search engines in the world. The choice of search term resulted from research and tests of related terms. The search term financial analyst provided the most relevant results regarding the research question. However, when searching for financial analyst, many related positions appeared as well, which were relevant for the scope of the research. Thus, the job portal was searched for the term of financial analyst and related positions as follows: risk analyst, global markets sales \& trading analyst, quantitative analyst, business analyst, risk analyst, debt analyst, corporate broking analyst, IT business analyst, credit analyst, treasury analyst, enterprise risk analyst and financial planning analyst.

Job advertisements were briefly screened for relevant content before considering in the sample. The screening criteria included were:

- Job advertisement is for entry-level or junior positions. Meaning, the position is aimed at recent graduates or professionals with less than 3 years of work experience.

- The creator of the job advertisement is a bank or similar financial institution and not a company outside of the financial sector.

- The job title is related to financial analyst positions (as mentioned above).

\subsubsection{Data Analysis}

The data was analyzed with QCAmap [24] for conducting a qualitative content analysis as proposed by Mayring [25]. The coding unit was set to phrase or clause and multiple categorizations were allowed within the system. In the coding guideline all subcategories of the DigComp 2.0 framework were entered including their definition and anchor samples as a reference.

A trial coding was undergone leading to a revision of the coding scheme. We had to rethink the meaning of some of the subcategories as they were sometimes difficult to distinguish from each other. The use of software tools such as Microsoft Office for example was difficult to clearly match to one of the subcategories as it used for various purposes. Therefore, we revised the anchor samples in a way that more quantitative 
tasks such as the use of Excel belonged to information and data literacy whereas more creative tasks such as the use of PowerPoint were matched to digital content creation. We also decided to allow for multiple categorization of content in the QCAmap tool in case a word or phrase represented more than one subcategory.

Subsequently, the data set was coded and recoded completely leading to the analysis results. In case subcategories occurred more than once in a job advertisement they were coded multiple times. This allowed us to gain insights into the relative importance of digital competences within a job advertisement. This assumes that digital competences that are named frequently than others within a job advertisement have higher relevance to the publishing company. After finishing the coding on the QCAmap tool online, an Excel spreadsheet, containing the frequency counts of the subcategories was prepared for further analysis. One main differentiation was made between looking at the frequencies across all subcategories and looking at the five overarching digital competence categories only.

\subsection{Additional Interviews}

In addition to the analysis of the job advertisements (see Sect. 3.1), four expert interviews have been conducted to validate and discuss our findings. In order to guide the respondents through the research's findings while keeping an open discussion possible, the interviews were conducted as semi-structured interviews, and were audiotaped [26]. The conversations were transcribed for later review and analysis. To conduct the interviews, an interview protocol according to Creswell and Creswell was prepared [27].

The first respondent (R1) was a Merger \& Acquisition (M\&A) financial analyst from an American investment bank in London. He has worked in his job for eight months in addition to previous summer analyst roles in various investment banks. The second interviewee (R2) was a M\&A financial analyst for Corporate Finance International (CFI) where he has been working for a little over six months. He previously held a summer analyst positions at Citibank from which he could additionally derive some insights during the interviews. The third interview (R3) was conducted with a structured finance analyst at the Royal Bank of Scotland (RBS) since September 2018. Considering his position was not in $\mathrm{M} \& \mathrm{~A}$, he had some differing opinions and explanations for the findings of the research, while still corroborating arguments made by the first two interviewees. The fourth and last interview (R4) was conducted with a director at an American investment bank in the UK. As director, he has a mainly managerial function, which includes making hiring decisions.

The main findings and selected quotes out of the four interviews are presented and discussed in Sect. 4.2. 


\section{Findings and Discussion}

\subsection{Job Advertisements}

The five categories of the DigComp 2.0 framework are used to illustrate "the big picture" of the digital competence requirements named in the job advertisements, whereas the 21 subcategories are used to understand them in more detail.

Table 2 depicts both the frequency counts and the share of each competence category within the data set of the 50 job advertisements.

Table 2. Frequency counts per digital competence categories

\begin{tabular}{l|l|l}
\hline Category & Frequency counts & Frequency \\
\hline Information and data literacy & 278 & $54 \%$ \\
\hline Digital content creation & 113 & $22 \%$ \\
\hline Communication and collaboration & 69 & $13 \%$ \\
\hline Problem solving & 52 & $10 \%$ \\
\hline Safety & 3 & $1 \%$ \\
\hline
\end{tabular}

Category 1 (information and data literacy) is the most important category and requirement for entry-level positions in the UK banking industry in terms of frequency (278). As the name "analyst" already reveals, being able to understand and interpret information and data is a significant aspect of analysts' responsibilities. Category 3 (digital content creation) follows as second strongest category and requirements with a share of nearly one fourth and a frequency count of 113. Category 2 (communication and collaboration) only represents $13 \%$ of all requirements in the data set with a total of 69 frequency counts. It is therefore the third most frequent subcategory in the data set. Accordingly, next to working with data and creating digital content, it is important that financial analysts can communicate and collaborate with others to create and distribute their analysis. Although being the third most frequent category it remains surprising that this category plays a relatively small role in the digital competence requirements. One potential explanation could be that the job of analysts is very individualistic and thus more based on individual performance and competences rather than the ability to work with others. Investigating this issue is part of the interview study (see Sect. 3.2).

Combined, information and data literacy, digital content creation and communication and collaboration represent $89 \%$ of all competence requirements in the data set. After this initial analysis it can be assumed that these three digital competences are the digital core competences of a junior financial analyst in the UK banking industry.

Figure 1 contains the frequencies of the 21 subcategories of the DigComp 2.0 framework. The undoubtedly most required competence with a total of 163 frequency counts is subcategory 2 (evaluating data, information and digital content), indicating the importance of understanding and analyzing data for the work of analysts. It is followed by subcategory 3 (managing data, information and digital content) with 95 frequency counts. Subcategory 3 was, within the job advertisements, often related to 
managing client data as well as the volume of data available in relation to investments. Subcategory 10 (developing digital content) is the extension of the data analysis and management into reports and presentations for other stakeholders and was mentioned a total of 54 times within the data set. These top three competences are often combined with the skill of using specific software programs such as Microsoft Excel, Word and/or PowerPoint. With a frequency count of 40, subcategory 11 (integrating and reelaborating digital content) represents the fourth most frequent subcategory.

Frequencies of DigComp 2.0 Subcategories in the Job Descriptions

17. Protecting the environment 16. Protecting health and well-being 12. Copyright and licences

9. Managing digital identity 6. Engaging in citizenship through digital technologies

18. Solving technical problems 15. Protecting personal data and privacy 14. Protecting devices ।

21. Identifying digital competence gaps

8. Netiquette

5. Sharing through digital technologies

4. Interacting through digital technologies

13. Programming

1. Browsing, searching and filtering data, information and digital content 19. Identifying needs and technological responses

20. Creatively using digital technologies

7. Collaborating through digital technologies

11. Integrating and re-elaborating digital content

10. Developing digital content

3. Managing data, information and digital content

2. Evaluating data, information and digital content

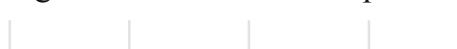




\subsection{Interviews}

The interview findings are matched to the categories and subcategories as in 4.1 and ranked according to the relevance they played in the interviews.

Information and Data Literacy. When confronted with category 1 (information and data literacy), there was consensus among all interviewees that this category was by far the most important one for a job as junior financial analysts.

\footnotetext{
"Analysts have to be extremely well versed in terms of information and data literacy. I would definitely put it as number one." (R1)

"So, it [work at Citi Bank] was financial analysis [...], making research online, working on databases and keeping them up to date." (R2)
}

Communication and Collaboration. When moving on to category 2 (communication and collaboration), respondents agreed on some aspects while refuting others. During the job advertisement analysis, it was surprising to see that communication and collaboration was mentioned so little in the job descriptions (see Sect. 4.1), as it is often mentioned to be a key competence when working in a digital environment. This view was also shared by some respondents.

\footnotetext{
"Communication and collaboration are extremely important. [...] Communication is huge, I think, and I am quite surprised why they do not mention this is the job description, but it is definitely a big part of what we do as financial analysts." (R1)

"So, you are on the trading floor with other hundreds of people around you; there is a lot of face to face; there are a lot of face to face meetings." (R4)
}

The interviewees further mentioned that communication competences might be taken for granted and are thus not specifically asked for in the job advertisements.

"People are expected to be already good at this." (R2)

"I guess it is important but taken for granted." (R3)

Digital Content Creation. Category 3 (digital content creation), was seen as less important than category 1 and category 2 by most respondents. Although information and analysis must be integrated and prepared for presentation, other competences in category 3 were evaluated as irrelevant or outside of the scope of junior financial analysts. One respondent stated that:

"Digital content creation - I think we are not as advanced as we should in that regard. Because we still use PowerPoint. We definitely do not do any programming or any crazy work in terms of graphics." (R1)

In conclusions, digital content creation played a less important role for financial analysts than data and information literacy, and communication and collaboration. One factor that plays into the low relevance of this factor for the respondents is the support of special departments in the creation of documents. A further interesting insight, when discussing this category, were the arguments made in relation to programming. It became apparent that programming is highly relevant in financial analyst positions on the trading floor, while being irrelevant in financial analyst role in advisory functions. 
Problem Solving. Looking at digital competence category 5 (problem solving), this was seen by all respondents as something that is the competence of a separate IT department and therefore not relevant for them most of the time.

"Problem Solving, that is IT. I mean, to give you a very simple example: When my Excel crashed, I don't even think about it twice, I just call the help desk. Let alone if I need to have an extra RAM for speed or extra flash desk or whatever. So, everything in terms of technology and problem solving is handled by the back office, by the IT guys." (R1)

Safety. When discussing category 4 (safety) with respondents, it became apparent that digital safety, in some of its aspects, was a discussed and relevant issue in their workplace, but something that was handled by other teams and departments.

"In terms of safety we have a huge safety and compliance division that just focuses on that stuff.

And then goes on protecting devices, protecting personal data." (R1)

The overall learnings from discussing this category with the interview partners was that, although there is awareness about safety topics, they are not of central importance to financial analysts and digital competence in this category might be covered by specialized departments.

\subsection{Summary and Discussion of Findings}

As the name of the job position "analyst" entails, it was to be expected that information and data literacy was the most important competence for junior financial analysts. Within the digital content creation category, programming was an interesting competence to investigate within the general discussion of digital competences. The low frequency counts of the content analysis were a little surprising. However, it became apparent during the interviews that programming is a competence needed in some divisions of a bank, while irrelevant in others.

Furthermore, there were opposing results for the competence of communication and collaboration. The content analysis of the job advertisements revealed not a high importance of this competence (13\% of all frequency counts), while interviewees emphasized the relevance of communication and collaboration at the workplace. It is important to emphasize that communication and collaboration must be understood here in a digital context. Financial analysts from around the world can simultaneously edit data and documents through modern software and ERP systems which is essential in today's banking industry.

In relation to our research question, we could show that for junior financial analyst positions in the UK banking industry data and information literacy, communication and collaboration, as well as digital content creation are the most required digital competences. Safety and problem solving on the other hand are nearly irrelevant categories. 


\section{Conclusion}

Undoubtedly, digital technology significantly impacts the way firms are operated, managed and how they sell their products and/or services, thus influencing their employment patterns [28]. Therefore, it is important that research on digital competences continuously contributes to the right equipment of the labor market with the right knowledge, skills and attitudes. With the study at hand, we contribute to a better understanding of job requirements for junior financial analysts. This is not only relevant for graduates, applicants and junior analysts themselves, but also for HR professionals in the banking industry. Other contributors of our study are training and education providers, who are asked to adjust their offerings following the required competencies in the market.

As every research study, also our paper has limitations that could serve as the basis for future research. One of the major limitations of our study is the snapshot data analysis that lacks the investigation of historical developments or potential future requirements. An obvious research recommendation is therefore to conduct longitudinal studies in order to observe the data over several points of time.

Furthermore, in our study the numbers of both analyzed job advertisements and interviews are relatively small. Thus, an avenue for further research is replicating our study using extended data pools. Future research might also benefit from the presented analysis approach by applying it to other contexts such as different occupations.

We interpret our study as a first step of a larger project. Identifying required competences is the beginning while developing a more comprehensive competence model could be the next step. This, however, requires further research efforts as described in the previous paragraphs. Finally, the long-term objective could be to empirically test the relation of individual competence levels and, for example, job performance.

\section{References}

1. Palfrey, J.G., Gasser, U.: Born digital: understanding the first generation of digital natives. ReadHowYouWant.com (2011)

2. Colbert, A., Yee, N., George, G.: The Digital Workforce and the Workplace of the Future. Academy of Management, Briarcliff Manor (2016)

3. Autor, D.H., Levy, F., Murnane, R.J.: The skill content of recent technological change: an empirical exploration. Q. J. Econ. 118, 1279-1333 (2003)

4. Murawski, M., Bick, M.: Digital competences of the workforce - a research topic? Bus. Process. Manag. J. 23, 721-734 (2017)

5. Murawski, M., Bick, M.: Demanded and imparted big data competences: towards an integrative analysis. In: Proceedings of the 25th European Conference on Information Systems (ECIS), Guimarães, Portugal, 5-10 June 2017, pp. 1375-1390 (2017)

6. Newhouse, B.: Closing the digital competence gap. Train. Ind. Mag. May/June, 40-42 (2017)

7. Gomber, P., Kauffman, R.J., Parker, C., Weber, B.W.: On the fintech revolution: interpreting the forces of innovation, disruption, and transformation in financial services. J. Manag. Inf. Syst. 35, 220-265 (2018) 
8. Deloitte Insights: Global CIO Survey. Deloitte Insights (2017)

9. Black, L.K., Khetan, S., Akwafo, E., Halmrast, N., Harris, C., Oppenheimer, A.: Digital innovation, generational shifts, and the transformation of financial services. Chicago Fed Letter (2018)

10. Buvat, J., Crummenerl, C., Slatter, M., Puttur, R.K., Pasquet, L., van As, J.: The digital talent gap. Are companies doing enough. Capgemini Research Institute and LinkedIn (2017)

11. Shahlaei, C., Rangraz, M., Stenmark, D.: Transformation of competence - the effects of digitalization on communicators' work. In: Proceedings of the 25th European Conference on Information Systems (ECIS), Guimarães, Portugal, pp. 195-209 (2017)

12. Rynes, S.L., Orlitzky, M.O., Bretz Jr., R.D.: Experienced hiring versus college recruiting: practices and emerging trends. Pers. Psychol. 50, 309-339 (1997)

13. Ilomäki, L., Paavola, S., Lakkala, M., Kantosalo, A.: Digital competence - an emergent boundary concept for policy and educational research. Educ. Inf. Technol. 21, 655-679 (2016)

14. Calvani, A., Cartelli, A., Fini, A., Ranieri, M.: Models and instruments for assessing digital competence at school. J. E-Learning Knowl. Soc. 4, 183-193 (2008)

15. Ferrari, A.: Digital Competence in Practice: An Analysis of Frameworks. Publication Office of the EU, Joint Research Centre, Luxembourg (2012)

16. European Parliament and Council of the European Union: Recommendation of the European Parliament and of the Council of 18th December 2006 on key competences for lifelong learning. Official Journal of the European Union, pp. 10-18 (2006)

17. Ala-Mutka, K.: Mapping Digital Competence: Towards a Conceptual Understanding. Institute for Prospective Technological Studies, Sevilla (2011)

18. Vuorikari, R., Punie, Y., Gomez, S.C., van den Brande, G.: DigComp 2.0: the digital competence framework for citizens. Update phase 1: the conceptual reference model. European Union, Joint Research Centre (2016)

19. Siiman, L.A., et al.: An instrument for measuring students' perceived digital competence according to the DIGCOMP framework. In: Zaphiris, P., Ioannou, A. (eds.) LCT 2016. LNCS, vol. 9753, pp. 233-244. Springer, Cham (2016). https://doi.org/10.1007/978-3-31939483-1_22

20. Balula, A. (ed.): The use of DigComp in teaching and learning strategies: a roadmap towards inclusion. ACM (2016)

21. Evangelinos, G., Holley, D.: A qualitative exploration of the EU digital competence (DIGCOMP) framework: a case study within healthcare education. In: Vincenti, G., Bucciero, A., Vaz de Carvalho, C. (eds.) eLEOT 2014. LNICST, vol. 138, pp. 85-92. Springer, Cham (2014). https://doi.org/10.1007/978-3-319-13293-8_11

22. Berruti, F., Ross, E., Weinberg, A.: The Transformative Power of Automation in Banking. McKinsey \& Co., New York (2017)

23. Debortoli, S., Müller, O., Vom Brocke, J.: Comparing business intelligence and big data skills. Bus. Inf. Syst. Eng. 6, 289-300 (2014)

24. QCAMap Software. https://www.qcamap.org/

25. Mayring, P.: Qualitative content analysis: theoretical foundation, basic procedures and software solution. https://www.ssoar.info/ssoar/handle/document/39517

26. Misoch, S.: Qualitative Interviews. De Gruyter Oldenbourg, Berlin, Boston (2019)

27. Creswell, J.W., Creswell, D.W.: Research Design: Qualitative, Quantitative, and Mixed Methods Approaches. Sage Publications, London (2018)

28. Makridakis, S.: The forthcoming artificial intelligence (AI) revolution: its impact on society and firms. Futures 90, 46-60 (2017) 